Relato de Caso / Case Report

\title{
Doença de Castleman localizada abdominal
}

\section{Abdominal Castleman's disease}

Cássio V. C. Oliveiral

Cezar E. F. Gonçalves ${ }^{2}$

Virgínia F. S. Almeida

Alexandre M. P. Oliveira ${ }^{4}$

Flávia C. F. Pimenta
A doença de Castleman é um distúrbio linfoproliferativo raro. Há três tipos histológicos: hialino-vascular (mais comum), variante de células plasmáticas e forma mista. A forma hialino-vascular é caracterizada tipicamente por apresentar uma evolução clínica benigna, sem sintomas constitucionais (doença localizada). É geralmente tratada com cirurgia elou radioterapia. A doença multicêntrica apresenta sintomas sistêmicos. Ainda não há um consenso sobre qual a melhor abordagem terapêutica. Nós reportamos o caso de um homem de 47 anos de idade com uma massa abdominal e sintomas compressivos. Após ressecção cirúrgica parcial, os exames histopatológico e imunohistoquímico revelaram doença de Castleman variante hialino vascular. Como as células foliculares eram CD20+, administramos rituximab (anticorpo monoclonal antiCD20). A maioria dos casos revisados não consideram este tipo de abordagem, exceto no caso de doença de Castleman multicêntrica associada a infecção pelo HHV-8 e sarcoma de Kaposi. Geralmente considera-se o paciente curado após retirada cirúrgica da massa na doença localizada, mas realmente há um risco do paciente desenvolver um linfoma não-Hodgkin no seguimento a longo prazo. O objetivo deste relato é apresentar um caso raro que deve ser incluído no diagnóstico diferencial de desordens linfóides e discutir o tratamento desta doença. Rev. bras. hematol. hemoter. 2005; 27(2):133-137.

Palavras-chave: Doença de Castleman; massa abdominal; rituximab.

\section{Introdução}

A Doença de Castleman (DC) é um distúrbio linfoproliferativo raro de origem controversa. É também conhecida como hiperplasia angiofolicular linfóide, hiperplasia de nódulo linfático gigante e linforreticuloma folicular. ${ }^{1-4}$

Histologicamente é benigna, porém pode comportar-se de maneira agressiva ou estar associada a outros distúrbios como linfoma maligno e sarcoma de Kaposi. ${ }^{5}$ São descritos três tipos histológicos: hialino-vascular, variante células plasmáticas e misto. . $^{2,3}$
Do ponto de vista clínico-patológico, pode se manifestar sob a forma de massas localizadas ou como doença multicêntrica. A forma localizada pode ser assintomática ou apresentar sintomas sistêmicos. ${ }^{6}$ Acomete preferencialmente o mediastino ântero-superior e mais raramente o abdome. ${ }^{2} \mathrm{~A}$ DC multicêntrica é uma forma disseminada com adenopatias generalizadas, visceromegalias, manifestações auto-imunes e infecções recorrentes. O tipo histológico mais freqüente na DC multicêntrica é o de células plasmáticas. ${ }^{4} \mathrm{~A}$ maioria dos pacientes apresenta sintomas sistêmicos, principalmente com

${ }^{l}$ Chefe do Serviço de Transplante de Fígado do Hospital da Unimed/João Pessoa -PB, cirurgião do Hospital do Câncer Napoleão Laureano/João Pessoa-PB.

${ }_{3}^{2}$ Médico residente de Clínica Médica do Hospital Universitário Lauro Wanderley (HULW)/UFPB Campus I/João Pessoa PB.

${ }^{3}$ Médica patologista da Unidade Científica de Diagnóstico (UCD-Promédica)/João Pessoa-PB.

${ }^{4}$ Professor Titular da disciplina de Hematologia da Universidade Federal da Paraíba Campus I/João Pessoa-PB.

${ }^{5}$ Chefe do Serviço de Hematologia do Hospital do Câncer Napoleão Laureano/João Pessoa-PB, professora assistente da disciplina de Hematologia da Universidade Federal da Paraíba Campus I/João Pessoa-PB.

Correspondência para: Cezar Emiliano Fernandes Gonçalves

Rua Infante Dom Henrique 768 - Tambaú

58039151 - João Pessoa-PB

Tel.: (83) 32267507

E-mail: cefgon@yahoo.com.br 
o tipo células plasmáticas, como: febre, sudorese noturna, fadiga crônica, anemia e emagrecimento. ${ }^{1,4}$

As alterações laboratoriais mais comuns são: anemia, aumento das proteínas de fase aguda, hipoalbuminemia, hipergamaglobulinemia policlonal, citopenias auto-imunes, aumento da IL-6, proteinúria e ocasionalmente insuficiência renal. $^{3}$

O objetivo do presente relato é apresentar um paciente com uma massa abdominal de aspecto linfóide cujo diagnóstico foi doença de Castleman, assim como revisar aspectos clínicos e terapêuticos desta doença.

\section{Relato do caso}

Em janeiro de 2005, um paciente do sexo masculino, 47 anos, natural e procedente de João Pessoa, PB, foi encaminhado ao setor de Hematologia do Hospital do Câncer Napoleão Laureano com história de dor abdominal que piorou nos últimos sete meses. Era portador de uma gastrite crônica diagnosticada através de EDA há oito anos, tratado de maneira apropriada. Em 2001, apresentou anemia sintomática $(\mathrm{Hb}=5,8 \mathrm{~g} / \mathrm{dL})$, sendo transfundido com duas unidades de concentrado de hemácias. A colonoscopia e pesquisa de sangue nas fezes foram normais. Nova EDA realizada em agosto de 2004 mostrou hérnia hiatal por deslizamento, gastrite enantematosa de antro gástrico e duodenite. Nesta época, durante exame médico, foi palpada uma massa abdominal que foi confirmada por exame ultra-sonográfico. A TC do abdome mostrou comprometimento de alças do intestino delgado situadas em flanco direito e hipertrofia linfonodal circunjacente (Figura 1).

Foi realizado também o trânsito intestinal cujo resultado foi um distúrbio da motilidade intestinal com massa abdominal mediana, deslocando alças intestinais inferiormente e para a direita (Figura 2)

O paciente foi encaminhado para videolaparoscopia. A cirurgia foi convertida para laparotomia exploradora e o achado cirúrgico foi de múltiplos linfonodos disseminados pelo

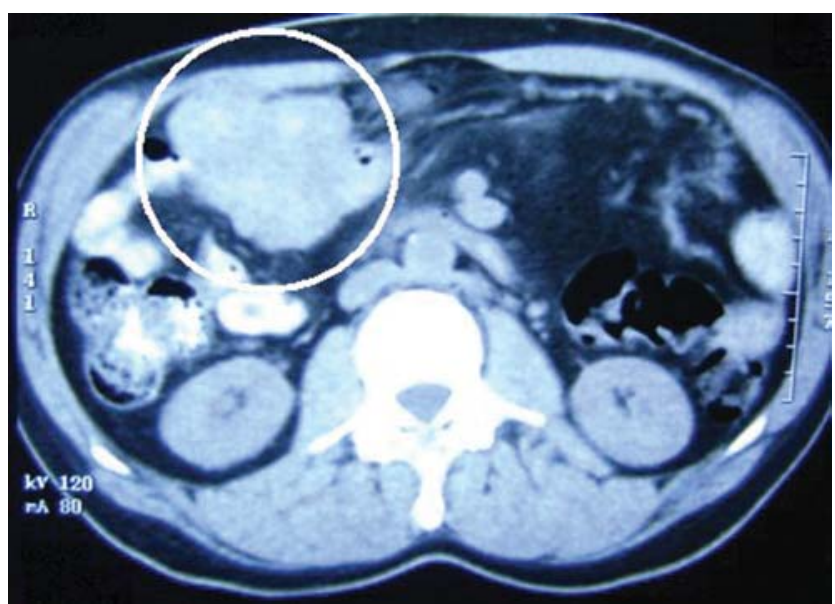

Figura 1. TC do abdome mostrando a imagem compatível com hipertrofia linfonodal no detalhe (círculo)

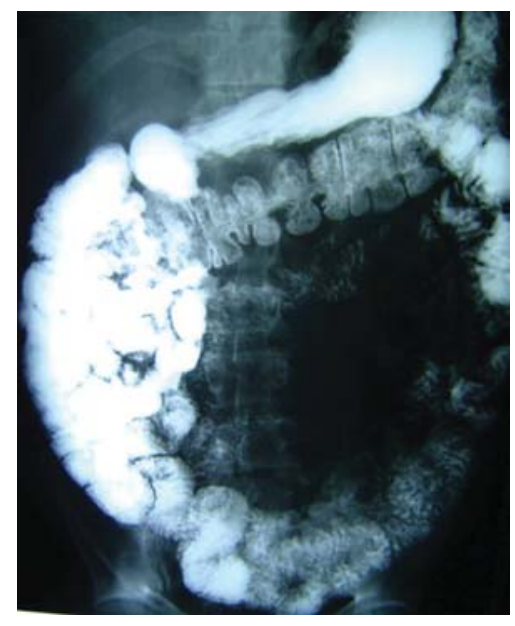

Figura 2. Trânsito intestinal mostrando deslocamento das alças intestinais para direita e inferiormente

mesentério, com tamanho variando entre $1 \mathrm{~cm}$ a $4 \mathrm{~cm}$, principalmente na área do jejuno. Foi submetido à exérese de dois linfonodos com aproximadamente $4 \mathrm{~cm}$ cada um e enviados para exame anatomopatológico. A ressecção total foi impossível em virtude de infiltrar entre as alças do delgado. Seguiu-se à cirurgia sintomas de suboclusão intestinal com distensão em flanco e fossa ilíaca direita, regurgitação e empachamento pós-prandial. A microscopia óptica revelou hiperplasia linfonodal padrão hialino-vascular e finas camadas de linfócitos na periferia dos centros germinativos com o aspecto de "casca de cebola" (Figuras 3 e 4).

Finalmente, foi realizado exame imuno-histoquímico que foi compatível com linfadenopatia tipo Doença de Castleman forma hialino-vascular (Tabela 1, Figura 5).

Ao exame físico, o paciente tinha um estado geral bom, orientado e consciente, corado, hidratado, eupnéico, temperatura $=36,5^{\circ} \mathrm{C}, \mathrm{PA}=125 \mathrm{X} 85 \mathrm{mmHg}$. Não foram palpadas adenomegalias. Exames respiratório e cardiovascular sem alterações. Abdome com cicatriz cirúrgica mediana, distendido, doloroso a palpação superficial e profunda em flanco e fossa ilíaca direita, fígado e baço não palpáveis. Ausência de

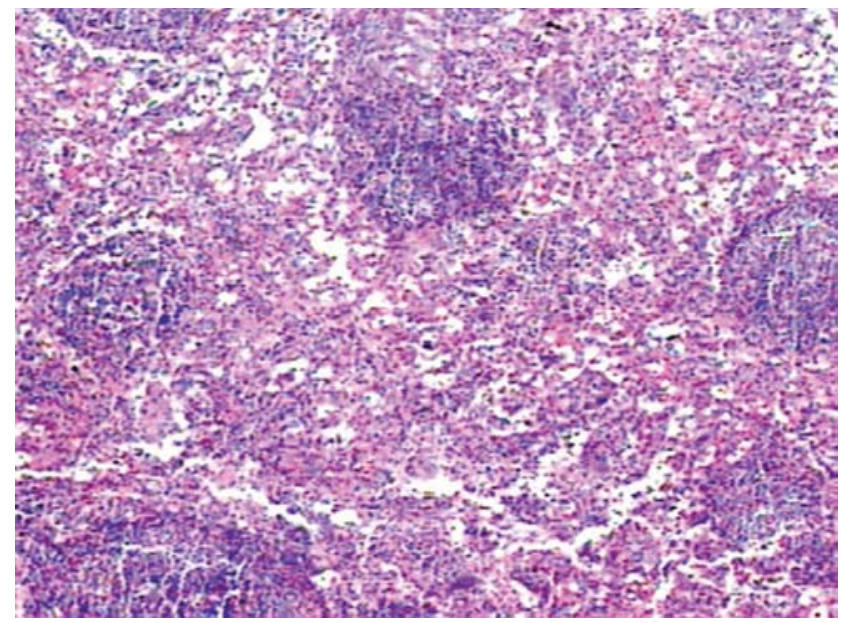

Figura 3. Histopatológico mostrando hiperplasia linfonodal tipo hialino-vascular 


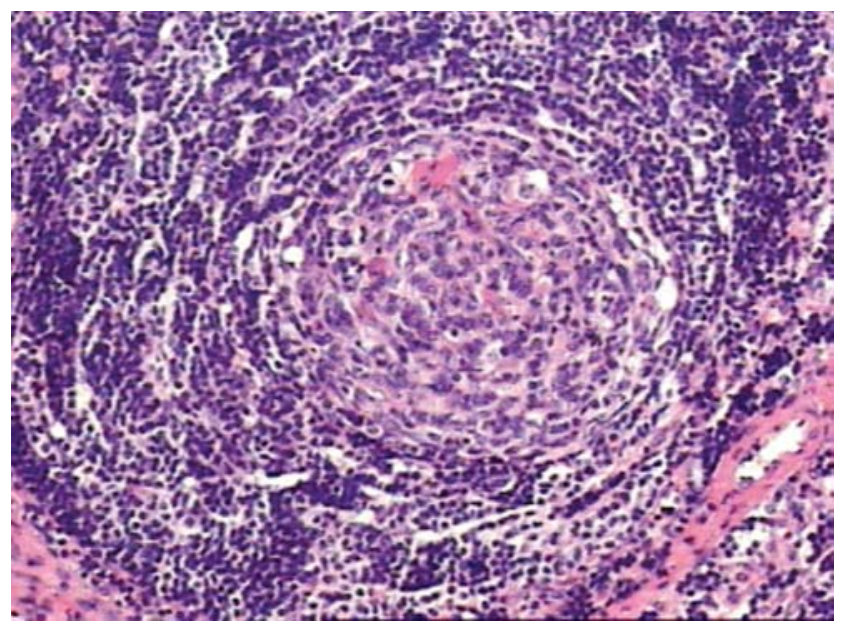

Figura 4. Finas camadas de linfócitos na periferia de centro germinativo (aspecto de "casca de cebola")

\begin{tabular}{|c|c|}
\hline Painel de anticorpos & Resultados \\
\hline Antígeno KI-67 & $\begin{array}{l}\text { Positivo em raras células } \\
\text { foliculares }\end{array}$ \\
\hline CD45 & Positivo difusamente \\
\hline CD30 & Negativo \\
\hline CD3 & $\begin{array}{l}\text { Positivo em células } \\
\text { interfoliculares }\end{array}$ \\
\hline CD20 & $\begin{array}{l}\text { Positivo em células } \\
\text { foliculares }\end{array}$ \\
\hline CD15 & Negativo \\
\hline CD10 & Negativo \\
\hline Produto do gene bcl-2 & $\begin{array}{l}\text { Positivo em células } \\
\text { foliculares e } \\
\text { interfoliculares e } \\
\text { negativo em centros } \\
\text { germinativos }\end{array}$ \\
\hline
\end{tabular}

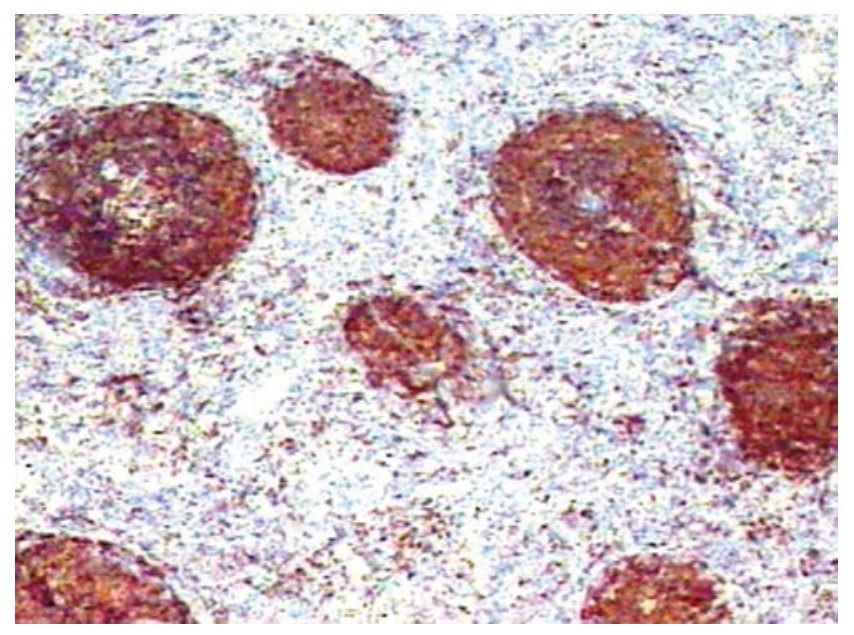

Figura 5. Imuno-histoquímica (CD20 positivo em células foliculares) déficits neurológicos e extremidades bem perfundidas, sem edema.

Exames laboratoriais: $\mathrm{Hb}=12,9 \mathrm{~g} / \mathrm{dL} ; \mathrm{Ht}=39 \%$; VCM $=86,7 \mathrm{fL} ; \mathrm{HCM}=28,7 \mathrm{pg} ; \mathrm{CHCM}=33,1 \%$; leucócitos $=6.400 / \mathrm{mm}^{3}$ ( $0 \%$ bastonetes, $76 \%$ segmentados, $2 \%$ eosinófilos, $21 \%$ linfócitos, $1 \%$ monócitos); plaquetas $=361.000 / \mathrm{mm}^{3}$; VHS $=17 \mathrm{~mm}$ $1^{\text {ah }}$ ora; ferritina sérica $=12,6 \mathrm{ng} / \mathrm{mL}$; uréia, creatinina, TGO, TGP, Fosfatase alcalina, DHL, bilirrubina total e frações, proteína $\mathrm{C}$ reativa normais. Pesquisa para HIV 1 e $2, \mathrm{HTLV} 1$ e 2, anti$\mathrm{HVC}$ e HBsAg negativas. $\mathrm{PPD}=4,5 \mathrm{~mm}$. Proteína total=6,7; albumina $=3,5$; globulina $=3,2 \mathrm{~g} / \mathrm{L}$. Eletroforese de proteínas: albumina $=55 \%$, alfa $1=5 \%$, alfa $2=12 \%$, beta $=14 \%$, gama $=14 \%$, ausência de pico monoclonal.

Foi instituído tratamento com rituximab (anticorpo monoclonal anti-CD20) $700 \mathrm{mg}$ EV semanalmente por quatro semanas. O paciente evoluiu sem intercorrências, com melhora dos sintomas gastrintestinais. Exame de imagem (TC do abdome) de março de 2005 foi normal.

\section{Discussão}

A DC é uma causa incomum de proliferação do tecido linfóide. Não há um consenso sobre sua etiologia. Uma das explicações é que se trata de uma hiperplasia linfóide reativa iniciada por estimulação crônica antigênica associada a uma infecção viral principalmente do trato respiratório e gastrointestinal. ${ }^{4}$ Foram detectados antígenos do herpes vírus humano tipo 8 (HHV-8) em células plasmáticas imaturas de alguns tipos de DC multicêntrica. ${ }^{6,7,8,9}$ Estes pacientes possuem um prognóstico pior. Outro vírus implicado é o EpsteinBaar. ${ }^{10}$

Outra causa sugerida é uma falha na regulação imunológica com o aumento da expressão do gene da IL-6, uma citocina com efeitos pleiotrópicos sobre o sistema imune e hematopoiese e que está relacionada à etiologia do mieloma múltiplo. Os pacientes com DC possuem níveis séricos de IL6 elevados, que declinam após retirada da massa de tecido linfático. Também é detectada nas células B dos centros germinativos. ${ }^{3} \mathrm{O}$ quimioterápico ciclosporina aumenta a expressão da IL-6 e tem sido diretamente implicada na patogênese de vários distúrbios linfoproliferativos, inclusive DC. ${ }^{11}$

A DC pode evoluir com manifestações auto-imunes como anemia hemolítica e trombocitopenia. Uma das hipóteses é que a estimulação crônica de clones de células B, particularmente CD5+ poderia favorecer tanto o desenvolvimento de doenças auto-imunes como uma gama de desordens linfoproliferativas. ${ }^{11}$ Também já foi observada a associação de DC com pênfigo paraneoplásico, uma doença mucocutânea bolhosa auto-imune. ${ }^{10}$

Pode acometer indivíduos de qualquer faixa etária. A doença localizada tem maior incidência em adolescentes e adultos jovens, enquanto a forma multicêntrica acomete mais indivíduos idosos ${ }^{4}$ e portadores de imunodeficiência, principalmente a síndrome da imunodeficiência adquirida. ${ }^{12}$ Indivíduos portadores do vírus HIV parecem ter maior risco de desenvolver DC multicêntrica, que geralmente surge concomitantemente com o sarcoma de Kaposi. ${ }^{6}$ 
Geralmente tem caráter histológico benigno, porém pode se comportar como uma doença maligna. ${ }^{5}$ A variante histológica hialino-vascular caracteriza-se por centros foliculares pequenos envolvidos por tecido hialino e com proeminente proliferação vascular inter-folicular. A zona do manto pode ser circundada por camadas concêntricas de linfócitos, aspecto denominado em "casca de cebola". ${ }^{7}$ A forma de células plasmáticas caracteriza-se por apresentar grandes folículos hiperplásicos entremeados por lâminas com numerosas células plasmáticas e tem menos vascularização. ${ }^{2,4,10} \mathrm{~A}$ forma mista tem aspecto intermediário entre as apresentações anteriores. ${ }^{6}$

A DC localizada geralmente tem o tipo histológico hialino-vascular, podendo ocasionalmente ser do tipo células plasmáticas. ${ }^{4}$ Geralmente acomete o mediastino, mas pode se desenvolver em outras regiões, principalmente onde os linfonodos estão presentes como a região cervical, o abdome, retroperitônio, axila, pelve. A DC multicêntrica é quase exclusivamente do subtipo histológico células plasmáticas. ${ }^{4}$ Pode estar associada à síndrome de POEMS (polineuropatia, organomegalia, endocrinopatia, proteína monoclonal e manifestações cutâneas). ${ }^{1,6,7,10,12}$

As manifestações clínicas podem ser sistêmicas (principalmente na variante de células plasmáticas) decorrentes da liberação de citocinas (TNF-alfa, IL-1 e IL-6). O paciente pode apresentar febre, citopenias, hepatoesplenomegalia, hipergamaglobulinema policlonal, disfunção hepática e renal. Há relatos de neuropatia periférica, miastenia gravis, derrame pleural e ascite recorrentes, amiloidose e síndrome nefrótica. ${ }^{4}$ A forma localizada geralmente é oligossintomática, e o paciente pode apresentar sintomas compressivos como dor torácica ou abdominal. ${ }^{7,10}$ Não é raro que seja uma descoberta incidental através de um exame de imagem.

Do ponto de vista radiológico e clínico, a DC é indistinguível do linfoma. Tem aspecto radiológico e cirúrgico semelhante a outras doenças incluindo várias neoplasias, hiperplasia linfonodal reativa, infecção pelo HIV, doenças auto-imunes como artrite reumatóide e síndrome de Sjögren, doenças inflamatórias como tuberculose e sarcoidose. ${ }^{10,12} \mathrm{O}$ diagnóstico definitivo é dado por biópsia. Alguns timomas e linfomas têm aspecto semelhante à DC no anatomopatológico, sendo necessário estudo imuno-histoquímico para a confirmação do diagnóstico nestes casos. ${ }^{4}$

A excisão cirúrgica é o tratamento de escolha para doença localizada, e raramente são observadas recidivas., ${ }^{4,10,12}$ No entanto, um seguimento a longo prazo é necessário pois há o risco de desenvolvimento de linfoma não-Hodgkin. ${ }^{14} \mathrm{~A}$ angiografia pode ser útil no pré-operatório para identificar o suprimento vascular do tumor, podendo-se inclusive proceder a embolização, que previne acidentes hemorrágicos na cirurgia. ${ }^{4}$ Pacientes que têm contra-indicação para cirurgia podem ser beneficiados com a radioterapia. ${ }^{4,10}$

$\mathrm{O}$ anticorpo monoclonal anti-CD20 (rituximab) tem sido utilizado em alguns pacientes com DC. Alguns autores sugerem que esta abordagem terapêutica deve ser considerada no tratamento da DC multicêntrica associada a sarcoma de Kaposi e infecção por herpes vírus humano tipo 8 (HHV-8) $)^{15}$ e também quando associada a síndrome de POEMS. ${ }^{8}$ Também já foi observado que o rituximab é eficaz no tratamento das manifestações imunes como anemia hemolítica e fenômeno de Raynauld associados a DC. ${ }^{17}$

Considerando a pouca experiência no tratamento da doença de Castleman e a evidência de células foliculares CD20 positivas, optou-se pela administração de rituximab no paciente do presente caso tendo em vista a impossibilidade de ressecção cirúrgica da massa e sintomas compressivos importantes. Ele tinha o antecedente de anemia grave e refratária com necessidade de terapia transfusional. Este sintoma provavelmente foi conseqüência da produção pela doença de Castleman de citocinas que inibem a hematopoiese, que mesmo sendo localizada pode ter repercussões sistêmicas. Quando a excisão cirúrgica da massa linfóide é possível, a maioria dos pacientes com doença localizada é considerada curada após a cirurgia. ${ }^{4,710}$ Vasef et al, ${ }^{14}$ em 1992, no entanto, observaram o desenvolvimento de linfoma não-Hodgkin no seguimento de um paciente que havia sido operado para retirada de massa diagnosticada como doença de Castleman localizada.

O tratamento da DC multicêntrica ainda é controverso. Alguns autores sugerem iniciar o tratamento com corticosteróide e, em caso de falha terapêutica, iniciar quimioterapia com vincristina, ciclofosfamida e doxirrubicina. ${ }^{6,7,10}$ Beck et al, ${ }^{3}$ em 1994, obtiveram um efeito benéfico transitório com a administração de anticorpo monoclonal anti-IL-6 em um paciente com DC subtipo histológico células plasmáticas. Outras modalidades terapêuticas são interferon-alfa e ácido retinóico. ${ }^{10} \mathrm{O}$ prognóstico da DC multicêntrica não é bom, tendo em vista o potencial de associar-se a linfoma de células B, sarcoma de Kaposi, entre outros, e a sobrevida média é de 30 meses. $^{1}$

O presente caso reforça a necessidade de incluir a doença de Castleman no diagnóstico diferencial de distúrbios linfoproliferativos.

\section{Abstract}

Castleman's disease is an uncommon lymphoproliferative disorder. There are three histologic types, hyaline vascular (the most common), plasma cell variant and mixed form. The hyaline vascular variant is typically characterized by a benign clinical course without constitutional symptoms (localized disease). It is usually managed with surgery and/or radiotherapy. Multicentric disease is a systemic disorder. An optimal management is still unknown. We report a case of a 47-year-old man with an abdominal mass and compressive symptom. After partial surgical resection, histopathological and immunohistological studies revealed the hyaline vascular variant of localized Castleman's disease. Because the follicular cells were $\mathrm{CD} 20+$ we administered rituximab (anti-CD20 monoclonal antibody). Most of the cases reviewed do not consider this approach, except for HHV-8 and sarcoma of Kaposi associated multicentric Castleman's disease. They usually consider the patient free from disease after surgical resection of localized Castleman's disease, but there is a risk of developing non-Hodgkin lymphoma in the long-term. The purpose of this report is to present this rare case, to 
stress that Castleman's disease should be included in the differential diagnosis of lymphoid disorders and to discuss the management of this disorder. Rev. bras. hematol. hemoter. 2005; 27(2):133-137.

Key words: Castleman's disease; abdominal mass; rituximab.

\section{Referências Bibliográficas}

1. García C, Dufort G, Pacheco H et al. Enfermedad de Castleman em una adolescente. Arch Pediatr Urug 2001;72(4):288-292.

2. Schunemann E, Urban CA, Delle LAB, et al. Doença de Castleman retroperitoneal - relato de um caso e revisão da literatura. Acta Oncol Bras 2000;20.

3. Beck JT, Hsu SM, Wijdenes J, et al. Alleviation of systemic manifestations of Castleman's Disease by monoclonal antiinterleukin-6 antibody. N Engl J Med 1994;330(9):602-5.

4. Gidvani VK, Tyree MM, Bhowmick SK. Castleman's disease: atypical manifestation in an 11-year-old girl. South Med J 2001;94(2): 250-3.

5. Onishi T, Yonemura S, Sakata Y, Sugimura Y. Renal lymphoma associated with Castleman's disease. Scand J Urol Nephrol 2004;38: 90-91

6. Izuchukwu IS, Tourbaf K, Mahoney MC. An unusual presentation of Castleman's disease: a case report. BMC Infect Dis 2003;3(20).

7. Souza LJ, Lopes AC, Gabrial A, et al. Doença de Castleman multicêntrica. Rev Soc Bra Clín Méd 2005;3(1):20-23.

8. Hudnall SD, Chen T, Brown K, et al. Human herpesvirus-8-positive microvenular hemangioma in POEMS syndrome. Arch Pathol Lab Med 2003;127(8):1034-6.

9. Matsuo S, Nakamura Y, Nakae I, et al. Scintigraphic evaluation of cardiac metabolism in multicentric Castleman's disease. Int Med 2004;43(6):490-492

10. Muhsein KA, Liew NC, Shaker AR, Shahrin IA. Localized Castleman's disease presenting as a vascular right iliac fossa mass. Asian J Surg 2004;27(1):54-7.
11. Marchi G, Vita S, Fabris M, et al. Systemic connective tissue disease complicated by Castleman's disease: report of a case and review of the literature. Haematologica 2004;89(1).

12. Erkan N, Yildirim M, Selek E, Sayhan S. Peripancreatic Castleman disease. JOP. J Pancreas 2004;5(6):491-494.

13. Azevedo JRS, Martins MVDC, Lemos RV. Adrenalectomia videolaparoscópica na doença de Castleman. Rev de Cir Videoend da Sociverj 2001;4(3).

14. Vasef M, Katzin WE, Mendelsohn G, Reydman M. Report of a case of localized Castleman's disease with progression to malignant lymphoma. Am J Clin Pathol 1992;98:933-6.

15. Corbellino M, Bestetti G, Scalamogna C. Long-term remission of Kaposi sarcoma-associated herpesvirus-related multicentric Castleman disease with anti-CD20 monoclonal antibody therapy. Blood 2001;98(12):3473-5.

16. Oliveira $\mathrm{CH}$, Barros PMG, Graudenz GS, et al. Associação entre doença de Castleman e atopia. Rev Bras de Alerg e Imunop 1998; 21(5).

17. Ocio EM, Sanchez-Guijo FM, Diez-Campelo M, et al. Efficacy of rituximab in an aggressive form of multicentric Castleman disease associated with immune phenomena. Am J Hematol 2005; 78 (4): 302-5.

18. Marcelin AG, Aaron L, Mateus C. Rituximab therapy for HIVassociated Castleman disease. Blood 2003;12(8):2.786-8.

Avaliação: Editor e dois revisores externos.

Conflito de interesse: não declarado

Recebido: 09/06/2005

Aceito após modificações: 30/06/2005 